\title{
Dever De Renegociar Contratos De Trabalho Como Possibilidade De Superação Da Crise Econômica Decorrente Da Pandemia Do Coronavírus
}

\author{
Paulo Henrique Tavares da Silva * \\ Centro Universitário de João Pessoa, Programa de Pós-Graduação em Direito, João Pessoa-PB, Brasil.
} (iD) http://orcid.org/000o-0002-9491-8829

\author{
Juliana Coelho Tavares Marques ** \\ Associação Paraibana de Ensino Renovado, Faculadade de Direito, João Pessoa-PB, Brasil.
} iD https://orcid.org/0000-0003-0726-5573

Resumo: O artigo perquire alternativas ao cenário de crise econômica no que concerne aos crescentes níveis de dissolução dos contratos de trabalho em decorrência da perda da capacidade econômico-financeira das empresas, impedidas de atuar devido as medidas restritivas de circulação de pessoas ocasionadas pela emergência em saúde pública decretada no Brasil, face a pandemia do vírus SarsCov-2 (Coronavírus). Inquire-se a possibilidade de construir parâmetros para um dever de renegociar os contratos de trabalho em curso, objetivando a manutenção dos empregos e permanência em atividade das empresas, com base em princípios constitucionais vigentes, particularmente ligados à socialização e funcionalidade das instituições, a partir de um diálogo entre o direito civil e o direito do trabalho. $\mathrm{O}$ estudo tem natureza exploratória e prospectiva, se utilizando da abordagem dedutiva, com o manejo das técnicas de pesquisa documental, tendo como objeto de estudo a legislação, doutrina e aportes jurisprudenciais. Ao final, admite-se que o direito de pleitear a renegociação dos contratos de trabalho é ferramenta hábil à superação da crise, por atender ao aspecto socializante dos contratos e privilegiar a boa-fé dos contratantes, sem desprivilegiar os cânones constitucionais da proteção ao trabalho e ao direito de participação das entidades sindicais no processo de renegociação.

Palavras chave: Dever de Renegociar. Contratos de Trabalho. Crise Econômica. Coronavírus.

\footnotetext{
* Doutor e Mestre em Direitos Humanos e Desenvolvimento pela UFPB. Professor dos cursos de graduação e pós-gradução do Unipê-JP. Email: phsilva13@gmail.com

** Mestre em Direito pela UFPB. Professora Universitária na graduação em Direito da Associação Paraibana de Ensino Renovado e na UFPB. E-mail: juliana.tavaress@gmail.com
}

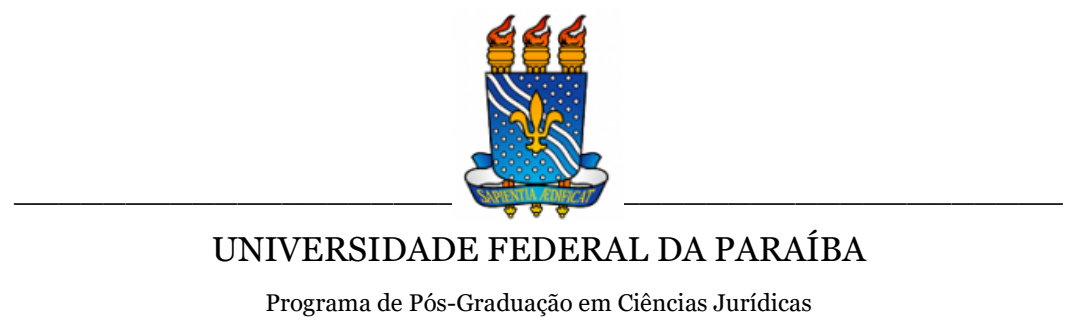

DOI: https://doi.org/ 10.22478/ufpb.1678-2593.2021v20n43.54543 


\title{
Dever De Renegociar Contratos De Trabalho Como Possibilidade De Superação Da Crise Econômica Decorrente Da Pandemia Do Coronavírus
}

\author{
Paulo Henrique Tavares da Silva
}

Juliana Coelho Tavares Marques

\section{INTRODUÇÃO}

O presente ensaio busca alternativas ao cenário de crise econômica por que passam os empregadores em decorrência da emergência em saúde pública decretada no Brasil, face a pandemia do vírus Sars-Cov-2 (Coronavírus). Embora tardiamente, preferiu o governo federal editar Medida Provisória 927, em 22 de março de 2020, criando alternativas aos empregadores para modificar unilateralmente os contratos de emprego em curso, dando-lhes poderes destinados a, transitoriamente, reformular os parâmetros econômicos da avença, especialmente no que tange aos regimes de pagamento de salário e períodos de repouso. Aquela norma transitória foi submetida ao Congresso Nacional, teve vigência prorrogada por mais sessenta dias em 08 de maio de 2020, através do Ato da Mesa do Senado Federal 32/2020, contudo, em 19 de julho, em virtude de sua não apreciação pelo Legislativo, deu-se a perda da eficácia, nos termos constitucionais.

O fato é que a crise econômica ainda persiste no cenário nacional, com níveis de dissolução dos contratos de trabalho crescentes, em razão da perda da capacidade econômico-financeira das empresas, impedidas de atuar em decorrência das medidas restritivas 
de circulação de pessoas impostas pelas autoridades públicas. Notadamente, o modelo contratual inserto na CLT é destituído de mecanismos flexíveis, capazes de enfrentar situações como essa, sendo suas alternativas, quando não radicais, impondo a extinção do vínculo; mostram-se insensíveis ao aspecto bilateral da relação contratual, a partir da vedação de alterações contratuais unilaterais lesivas.

Pois bem, o problema a ser aqui enfrentado diz respeito à superação desses entraves em tempos excepcionais como este que estamos vivenciando. É possível, com base apenas no ordenamento jurídico vigente, sem qualquer medida normativa extraordinária, construir novos parâmetros aos contratos de trabalho em curso, objetivando a manutenção dos empregos e permanência em atividade das empresas?

A saída aqui apontada parte de um esforço exegético que congrega os princípios constitucionais vigentes, particularmente ligados à socialização e funcionalidade das instituições normativas, a partir de um diálogo proveitoso entre o direito do trabalho e seu coirmão direito civil, este que possui instrumentos bastante interessantes ao enfrentamento de situações contingenciais.

Emerge, desta forma, o dever de renegociar, de índole civil, como uma alternativa a ser considerada. Todavia, há que se considerar as peculiaridades do contrato de trabalho, em especial, a presença salutar do órgão sindical nessas negociações. Destaque-se que esse mecanismo, embora de uso crescente na seara das relações de consumo e mesmo em vários contratos civis (o de locação, por exemplo), é de pouca utilização no território trabalhista, muito embora, até mesmo recentemente, em discussão perante o Supremo Tribunal Federal, restou avivada essa possibilidade, como se verá adiante.

Trata-se, assim, de estudo de natureza exploratória e prospectiva, visando construir, a partir do ordenamento jurídico vigente, alternativas à negociação e ajuste dos contratos de trabalho em tempos de crise (e não apenas pandemias), a partir do exercício do 
denominado direito de renegociação. Pesquisa que se utilizado da abordagem dedutiva, com o manejo das técnicas de pesquisa documental, tendo como objeto de estudo a legislação, doutrina e aportes jurisprudenciais.

Estrutura-se o ensaio em três partes. A primeira, dedica-se ao exame da figura do direito à renegociação, tendo como ponto de partida a noção de função social dos contratos. Na sequência, tratarse-á de elencar as peculiaridades do contrato de emprego e as alterações promovidas pelo Executivo visando enfrentar a crise econômica decorrente do contexto pandêmico. Por fim, apresentar-seá a proposta de adequação do instituto ao mundo do trabalho, viabilizando a ambiência dos contratos de emprego em contextos de crise.

Pretende-se, ao final, evidenciar a importância da mantença de um diálogo construtivo entre o direito civil e o direito do trabalho, visando não apenas a superação dos momentos de crise, bem assim uma readequação dos institutos deste ao momento contemporâneo que exige flexibilidade e consenso entre a livre iniciativa e a valorização social do trabalho.

\section{CAMINHOS DA TEORIA CONTRATUAL CIVIL: A CONSTRUÇÃO DE PRINCÍPIOS LIGADOS À FUNÇÃO SOCIAL E O NASCIMENTO DO DEVER DE RENEGOCIAR}

O surgimento do instituto contratual está indissoluvelmente ligado ao conceito de operação econômica. Em síntese, à medida em que houve a crescente expansão das atividades de produção, troca, distribuição de serviços, as regras jurídicas necessitavam dar uma resposta adequada para a proteção das novas exigências e interesses que emergiam (ROPPO, 2009).

Assim, o que se percebe é a relatividade do contrato: "o contrato muda a sua disciplina, as suas funções, a sua própria estrutura 
segundo o contexto econômico-social em que está inserido" (ROPPO, 2009, p. 24). Importante ressaltar que as primeiras elaborações da moderna teoria do contrato foram pensadas pelos jusnaturalistas do século XXVII, contemporaneamente ao nascimento do capitalismo. Ademais, a primeira grande sistematização legislativa de um "direito dos contratos" foi levada a cabo no período da Revolução Francesa, pelo código civil francês (Code Napoleón), em 1804, constituindo-se em bandeira e legitimação das sociedades burguesas ascendentes.

A primeira ideia que emerge deste paradigma contratual é a ideia de liberdade irrestrita de contratar e autonomia plena quanto ao conteúdo. Os contratantes, deveriam utilizar sua soberania de juízo e de escolha e decidir a estipulação ou não do negócio com aquela contraparte, cabendo apenas a elas determinar a extensão do conteúdo das cláusulas firmadas. Pode-se dizer assim, que estávamos diante de uma liberdade negativa, derivada do ideário do laissez faire, laissez passer: os poderes públicos (legislador e juízes) não poderiam se imiscuir na livre escolha dos contraentes privados.

O contraponto da liberdade contratual era a responsabilidade também ilimitada pelos compromissos assumidos. Tratava-se de um vínculo tão forte que poderia ser equiparado à lei ${ }^{1}$ O raciocínio é uma conclusão extraída da própria lógica do mercado, que necessita de previsões e cálculos das operações econômicas: se cada um é absolutamente livre para comprometer-se ou não, uma vez que o fizesse ficaria ligado de modo irrevogável à palavra dada, ou, como se convencionou chamar de pacta sunt servanda.

Nesse momento não era possível sequer cogitar em igualdade material ou justiça substancial. Isso porque a justiça da relação era automaticamente assegurada pelo fato do conteúdo do negócio jurídico corresponder exatamente à vontade livre dos contratantes, determinada pelos seus próprios interesses, reflexo da igualdade jurídica formal (paridade dos cidadãos perante a lei) (ROPPO, 2009,

${ }^{1}$ É a fórmula do artigo 1134 do Código de Napoleão: "os contratos legalmente formados têm força de lei para aqueles que os celebram”. 
p. 32). Em síntese, liberdade contratual e igualdade formal eram sinônimo de justiça nas relações econômicas.

Quanto a liberdade de contratar, Enzo Roppo (2009, p. 37) alerta que ela demonstra a dissolução do vínculo de grupo, e de estado, que aprisionava o indivíduo e lhe impedia a plena expansão de suas potencialidades produtivas. É a restituição do poder do indivíduo da abstrata possibilidade de determinar sozinho o seu destino no mundo das relações jurídicas.

Com efeito, essa era a concepção clássica do Direito Civil, que privilegiava não só o individualismo, mas a defesa do patrimônio. Tinha como características ser estruturalmente estático, atemporal, de perfil linear e matriz cartesiana, além de que "o sujeito merecia a atenção do Estado em função de seu patrimônio e não por sua condição de pessoa" (FEITOSA, 2017, p. 242). Assim, a ordem jurídica era voltada para uma perspectiva patrimonialista, formalista e para a máxima garantia da liberdade e da autonomia da vontade dos atores em prol do mercado.

No Brasil, o Direito Civil se alinhava com o cenário acima, especialmente pela inspiração napoleônica. O Código Civil de 1916, nascido sob a égide do liberalismo econômico, buscava resguardar os direitos e liberdades individuais contra a intervenção estatal, plasmando um modelo estático, adverso às mudanças sociais, políticas e econômicas, naturais ao longo do tempo.

Nesse sentido, o direito privado compenetrava-se na proteção patrimonial e na crença do individualismo como dogma, lastreado em pilares de um regime dedicado à aquisição de bens e a circulação de riquezas. Com efeito, visava eminentemente o contratante e o proprietário em sua atuação mercadológica, para poder contratar e fazer circular riquezas sem restrições ou entraves legais. O Código Civil era a garantia legal mais elevada quanto as relações patrimoniais (TEPEDINO, 2004, p. 2-3). 
$\mathrm{O}$ individualismo patrimonialista exacerbado estampado no ilusório dogma da autonomia da vontade ${ }^{2}$ acabou por gerar sérios desequilíbrios sociais. Assim, ganha força no século XX o dirigismo contratual, como reflexo dos movimentos sociais desencadeados na Europa, reposicionando o homem como parte integrante da sociedade, bem como aumentando o poder e intervenção estatal nas relações privadas.

O Estado intervencionista nasce justamente da falência do modelo liberal, que acarretou severos problemas na esfera social. A população pressionou o poder público a adotar soluções de proteção, fazendo com que o Estado aumentasse sua ingerência na ordem econômica para restabelecer o equilíbrio das relações contratuais, a partir da edição de normas jurídicas (ALMEIDA, 2015, p. 54).

Mauro Cappelletti (1999) demonstra a mudança que ocorreu no papel do direito e do estado na sociedade moderna, com a implantação do Welfare State. Este modelo estatal, seria resultado especialmente da atividade legislativa com fins de política social em conjunto com a intervenção forte do estado na economia. Dessa maneira, a legislação passou a ter caráter que tipicamente se destina a produzir transformações na sociedade, com uma preponderância do social ao individual.

Observe-se que as intervenções estatais, no estado de bemestar tinham principalmente a natureza de preceitos legislativos, no que se convencionou chamar de "orgia das leis", em sentido diametralmente oposto ao que se viu na fase liberal antecedente. "Com o desenvolvimento de um aparato administrativo de alto grau de complexidade "o Welfare State, na origem essencialmente um "estado legislativo", transformou-se, assim, em "estado administrativo", na

\footnotetext{
2 Esclarece-se que se compactua com a distinção entre autonomia da vontade e autonomia privada, todavia, neste ponto, de fato, queremos ressaltar o dogma da autonomia da vontade: princípio que tem suas bases na sociedade liberal, marcado por uma ideologia individualista, onde o homem era o centro do direito, sendo a sua vontade livre e respeitada pelo Estado.
} 
verdade em "estado burocrático", não sem o perigo de sua perversão em "estado de polícia" (CAPPELLETTI, 1999, p.39).

Quanto aos contratos, Mattieto (2000, p.175) ressalta que com a evolução da ordem jurídica e, por conseguinte a ingerência estatal, o credor teve o exercício de seu direito subjetivo limitado, não cabendo aos contratantes, com exclusividade, a autodeterminação da lei entre as partes, que sofre intervenção do legislador e pode ser revisada pelo juiz.

Ademais, o mundo passou pelo processo de massificação das relações contratuais, o que subverteu radicalmente a balança econômica do contrato, transformando-o em um negócio jurídico estandardizado, documentado em um simples formulário, em que a uma parte (mais fraca) incumbe aderir ou não à vontade da outra (mais forte), sem possibilidade de discussão do seu conteúdo.

Nesse sentido, importante observação de Georges Ripert (2000, p.112-113):

\begin{abstract}
Que há de contratual neste ato jurídico? É na realidade a expressão de uma autoridade privada. O único ato de vontade do aderente consiste em colocar-se em situação tal que a lei da outra parte venha a se aplicar. $O$ aderente entra neste círculo estreito em que a vontade da outra parte é soberana. E, quando pratica aquele ato de vontade, o aderente é levado a isso pela imperiosa necessidade de contratar. É uma graça de mau gosto dizer-lhe isso: tu quiseste. A não ser que não viaje, que não faça um seguro, que não gaste água, gás ou eletricidade, que não use de transporte comum, que não trabalhe ao serviço de outrem, é-lhe impossível deixar de contratar.
\end{abstract}

Conforme informa Antonio Rulli Neto (2011, p. 21) o novo paradigma de relações sociais põe em cheque o modelo contratual anterior. Com efeito, as relações de massa impedem a manutenção dos simplórios modelos antigos e necessitam de mecanismos de controle mais específicos para garantir o equilíbrio das relações jurídicas e humanas.

É importante destacar que não só a livre estipulação do conteúdo, mas a própria liberdade de contratar restou mitigada, com 
o surgimento dos contratos obrigatórios, ou, coativos 3 . Estes são a expressão máxima das normas de ordem pública interferindo diretamente na formação e execução dos pactos, direcionados para a concretização dos valores socioeconômicos elencados como princípios da ordem econômica constitucional brasileira (SANTIAGO, 1979).

Também o princípio da igualdade formal entre as partes contratantes, pilar essencial do pacta sunt servanda se enfraqueceu, descortinando falhas no sistema social, e, sobretudo, afigurando-se, em muitos casos, como uma regra flagrantemente injusta, abrindo espaço para a igualdade material.

O Código Civil de 2002 tentou afastar-se das concepções individualistas do diploma anterior para buscar uma socialização do direito privado contemporâneo. Assim, reflete a primazia dos valores coletivos sobre os individuais, à luz do princípio da Dignidade da Pessoa Humana. Nesse contexto o contrato sofreu sensível transformação ao longo do século XX, e continua em mutação até os dias de hoje, experimentando um inegável processo de solidarização social, adaptando-se à sociedade que se formou.

\subsection{A (re) adequação da autonomia privada: função social, boa - fé objetiva e equilíbrio econômico do contrato}

O Estado Social de Direito, voltado para a harmonização da esfera individual com o social através das normas de ordem pública remanesce até os dias atuais, causando mudança nos três pilares do direito contratual clássico: liberdade de contratar, força obrigatória das convenções e relatividade de seus efeitos. Hoje, é possível falar em um paradigma que abarca os princípios da função social, boa-fé objetiva e equilíbrio econômico.

${ }^{3}$ São exemplos desta categoria: renovação compulsória da locação comercial, seguro obrigatório de veículo etc. 
Com efeito, destaca-se o nosso ordenamento por ter consagrado explicitamente a função social, conforme artigo 421 do Código Civil, como limite para o exercício da liberdade de contratar: "a liberdade de contratar será exercida nos limites da função social do contrato". Muito embora antes da edição da Lei da Liberdade Econômica a função social fosse não só o limite, mas a razão do exercício de contratar, na perspectiva dos autores deste ensaio, permanece a concepção de que a autonomia privada não é valor em si mesmo e somente é merecedora de tutela caso promova princípios e valores constitucionais, à exemplo da dignidade da pessoa humana (art. $1^{\mathrm{o}}, \mathrm{III}$ ), do valor da livre iniciativa (art. $1^{\mathrm{o}}, \mathrm{IV}$ ), da solidariedade social (art. $3^{\circ}$, I) e da igualdade substancial (art. $3^{\circ}$, III), ou seja, caso seja socialmente útil. Nesse sentido, conforme leciona Maria Celina Bodin de Moraes (2010, p.315-316), "assim, a liberdade de contratar não se dará, pois, em razão da vontade privada, como ocorria anteriormente, mas em razão da função social que o negócio está destinado a cumprir".

Destarte, a autonomia privada não é valor em si mesmo e somente é merecedora de tutela caso promova princípios e valores constitucionais, à exemplo da dignidade da pessoa humana (art. $1^{\mathrm{o}}$, III), do valor da livre iniciativa ( $\operatorname{art.} 1^{\circ}$, IV), da solidariedade social (art. $3^{\circ}$, I) e da igualdade substancial (art. $3^{\text {o }}$, III), ou seja, caso seja socialmente útil.

Assim é que pode falar em caráter intrínseco e extrínseco da função social (THEODORO JR., 2014). O primeiro vê o ato negocial como relação jurídica entre as partes contratantes, impondo-se o respeito à lealdade e boa - fé objetiva, além da observância da equivalência material. O segundo, visa o contrato em face da coletividade, examinando os efeitos na sociedade em que fora celebrado.

Ou seja, não se pode deslocar o contrato da conjuntura social em que está inserido, de forma que se limita a liberdade contratual em prol do bem comum. Isto quer dizer que não se pode aceitar contratos 
que apesar de atender os pressupostos formais de validade, desrespeitem leis ambientais e trabalhistas, por exemplo.

Outro ponto importante a ser considerado é a boa-fé objetiva, estampada no nosso diploma civilista em diversos momentos. Na sua função integrativa, podemos observar o artigo 422, nos seguintes termos: "os contratantes são obrigados a guardar, assim na conclusão do contrato, como em sua execução, os princípios de probidade e boafé”. Já quanto a sua função interpretativa, temos o artigo 113: “negócios jurídicos devem ser interpretados conforme a boa-fé e os usos do lugar de sua celebração”. Por fim, tem-se ainda sua função limitativa, conforme artigo 187: "excede manifestamente os limites impostos pelo seu fim econômico ou social, pela boa-fé ou pelos bons costumes”.

A boa-fé objetiva é, na realidade, uma regra de comportamento, uma exigência de que ambas as partes do contrato tenham uma conduta correta à luz dos padrões éticos do meio social, em todas as fases contratuais (THEODORO JR., 2014). Assim é que se fala em deveres jurídicos anexos de lealdade, confiança, assistência, sigilo, informação, etc.

Finalmente, é importante sublinhar o princípio da equivalência material, nas palavras de Rodrigo Toscano de Brito (2007, p. 29):

Diante disso, pode-se dizer que o princípio da equivalência material ou do equilíbrio contratual é aquele pelo qual se deve buscar e manter a justiça contratual, objetivamente considerada, em todas as fases da contratação, independentemente da natureza do contrato, e sempre com base na eticidade, lealdade, socialidade, confiança, proporcionalidade e razoabilidade nas prestações.

Em síntese, se antes a liberdade de contratar representava o axioma máximo da autonomia individual, hoje, este direito deixa de representar um poder reconhecido a um indivíduo, para instrumentalizar uma política econômica do Estado, na defesa e proteção dos vulneráveis.

O que se pode extrair da conjuntura acima é que o direito civil não ficou imune ao movimento de humanização, e é possível observar 
sua uma reconstrução do sistema segundo o valor da pessoa humana. Nas palavras de Pietro Perlingieri (2007, p. 34): “o pluralismo econômico assume o papel de garantia do pluralismo também político e do respeito à dignidade humana”.

Em um primeiro momento, a solidariedade superou "o mito do fim superindividual, não concebendo um interesse superior àquele do pleno desenvolvimento do homem. Este último constitui princípio fundamental de ordem pública" (PERLINGIERI, 2007, p.36). O tema da solidariedade também deve ser entendido em relação à igualdade $\mathrm{e}$ dignidade social, a fim de garantir uma existência digna, comum a todos, numa sociedade que se desenvolva como livre e justa, sem exclusão social.

O dever e valor de solidariedade fomentam, então, no Brasil, o Estado Democrático e Social de Direito. Trata-se de um projeto de uma sociedade embasada na dignidade da pessoa humana, cooperação, igualdade substancial e justiça social, que abarca a livre iniciativa, mas se contrapõe a lógica da competição desmedida e do lucro desenfreado.

Nesse sentido preleciona Rulli Neto (2011, p.18) sobre a necessidade criar-se mecanismos de controle e equilíbrio em razão das crises econômicas:

\footnotetext{
A sociedade deixa um pouco a visão puramente econômica que dá lugar ao solidarismo e a tendência de se criarem mecanismos de controle e equilíbrio. Eventos que levaram à crise econômica entre 2008 e 2009 testaram as instituições e mostraram novamente a necessidade de termos meios de reequilíbrio das relações obrigacionais, que, em última análise, acabam por atingir a sociedade em efeito dominó
}

Em síntese, a revolução do direito civil se dá em dois momentos, no primeiro, o do direito civil constitucionalizado, ocorre a restauração da primazia da pessoa, em detrimento do seu patrimônio; neste novo momento, ora intitulado, de humanização do direito civil, exige-se a garantia da efetivação dessa primazia humana. Trata-se de ir além do simples enlace com o constitucionalismo social, mas sim abarcar as "hipervulnerabilidades geradoras de exclusão social, para 
assumir feição de direito social, efetivando a dignidade e qualidade de vida e sujeitos e categorias" (FEITOSA, 2017, p.254).

Conforme propõe Feitosa (2017, p.254) "o novo direito civil deve abranger a hipervulnerabilidade como motor importante da garantia da dignidade da pessoa humana, e com isso, se aproximar dos direitos sociais", a fim de "ultrapassar a resignação programática tradicionalmente afeita aos direitos sociais, fato que continua a ocorrer no Brasil, mesmo na vigência da Constituição Federal atual”. A mesma autora ainda recomenda uma guinada dogmático-conceito do direito privado à luz dos direitos humanos, "na perspectiva de soluções que transcendam a satisfação individual ou mesmo coletiva (no sentido grupal) da questão, para alcançar abrangência de categorias, em viés transindividual e intergeracional" (FEITOSA, 2017, p. 254)

\subsection{Desequilíbrio contratual superveniente e crise: em defesa de um dever de renegociar}

O Código Civil brasileiro, muito embora, não tenha feito expressa menção a um princípio do equilíbrio contratual, pode-se extrair dos dispositivos do diploma normativo, em cotejo com os princípios constitucionais (em especial a igualdade substancial e a solidariedade social), que o nosso ordenamento jurídico reprime, em alguma medida, o desequilíbrio contratual superveniente exagerado, através das teorias da onerosidade excessiva e da imprevisibilidade.

Conforme já explicitado no tópico anterior, o princípio da equivalência material dirige-se ao objeto do contrato como um todo, prestações principais ou acessórias, direitos faculdades, obrigações e ônus, além de quaisquer outras situações jurídicas derivadas do contrato. Nas palavras de Anderson Schreiber (2018, p. 59): “o princípio do equilíbrio contratual, como aqui apresentado, resume-se, assim, a veicular um controle de proporcionalidade de caráter interno e objetivo (econômico) do contrato". 
Neste sentido, é importante destacar a redação dos artigos 317 , 478, 479 e 480 do Código Civil Brasileiro:

\begin{abstract}
Art. 317. Quando, por motivos imprevisíveis, sobrevier desproporção manifesta entre o valor da prestação devida e o do momento de sua execução, poderá o juiz corrigi-lo, a pedido da parte, de modo que assegure, quanto possível, o valor real da prestação.

Art. 478. Nos contratos de execução continuada ou diferida, se a prestação de uma das partes se tornar excessivamente onerosa, com extrema vantagem para a outra, em virtude de acontecimentos extraordinários e imprevisíveis, poderá o devedor pedir a resolução do contrato. Os efeitos da sentença que a decretar retroagirão à data da citação.

Art. 479. A resolução poderá ser evitada, oferecendo-se o réu a modificar equitativamente as condições do contrato. Art. 480. Se no contrato as obrigações couberem a apenas uma das partes, poderá ela pleitear que a sua prestação seja reduzida, ou alterado o modo de executá-la, a fim de evitar a onerosidade excessiva.
\end{abstract}

Da análise dos referidos dispositivos, é possível extrair os seguintes requisitos para aplicação da teoria da onerosidade excessiva: o contrato deve ser de execução continuada ou diferida, deve haver onerosidade excessiva para uma das partes, com extrema vantagem para outra parte, em virtude de acontecimentos extraordinários e imprevisíveis.

É importante ressaltar que não obstante os esforços da codificação em diminuir os efeitos do caráter patrimonialista e individualista da legislação anterior, os enunciados acima destacados não rechaçam o desequilíbrio contratual por si só, mas, apegam-se “em alguma medida à ideologia do liberal - voluntarismo jurídico, acostando ao desequilíbrio objetivo outros requisitos, de caráter subjetivo, ligados ao estado psicológico e anímico das partes no momento da contratação” (SHEREIBER, 2018, p. 35). Além disso, a obtenção do reequilíbrio contratual é feita sempre de forma indireta, ficando a iniciativa a cargo do contratante favorecido, sendo encarado como "mera faculdade".

Com efeito, o requisito da imprevisibilidade somente estaria preenchido caso o fato não pudesse ser legitimamente esperado pelas partes no momento da conclusão do ajuste, levando-se em conta suas características subjetivas. Outrossim, diante do panorama traçado 
pelo desenvolvimento da teoria contratual, o contrato não é mais um instrumento meramente individual, mas sim um instrumento de desenvolvimento social. Assim, uma solução terminativa não seria capaz de atender nem aos interesses do contratante onerado, nem muito menos concretizaria os valores constitucionais da igualdade e solidariedade.

Embasado nas premissas acima, reconhecendo a importância do desenvolvimento de remédios dirigidos ao reequilíbrio do contrato e somando ao fato de que na falta de cláusula contratual expressa, inexistem garantias de que "o contratante favorecido responderá à tentativa de renegociação efetuada por quem sofre a excessiva onerosidade" (SCHREIBER, 2018, p.278), é que foi proposta e desenvolvida uma teoria do dever de renegociar.

Segundo Schreiber (2018, p. 282, 284), trata-se do direito de pleitear a renegociação do contrato independentemente de previsão contratual, baseado na conduta transparente e colaborativa entre as partes, alicerçada na boa fé objetiva. Todavia, ao contratante que sofre os prejuízos da excessiva onerosidade, não seria possível uma conduta passiva, teria este o dever de mitigar os danos sofridos, informando prontamente à contraparte a ocorrência do desequilíbrio. À parte credora, por outro lado, caberia, o dever correlato de prontamente responder à renegociação.

Dessa forma, vislumbra-se em tal dever, uma possível solução para a situações de crise, como a que estamos passando em decorrência da COVID-19, a fim de permitir a manutenção da fonte produtora, do emprego dos trabalhadores e dos interesses dos credores, promovendo, assim, a preservação de empresas, sua função social e o estímulo à atividade econômica. 


\section{EM NOME DA CRISE: ALTERAÇÕES UNILATERAIS DOS CONTRATOS DE TRABALHO A PARTIR DA EMERGÊNCIA EM SAÚDE PÚBLICA}

No plano jurídico interno, a declaração de Emergência em Saúde Pública de Importância Nacional deu-se a partir da publicação da Portaria do Ministério da Saúde de $\mathrm{n}^{0}$ 188, no dia 03 de fevereiro de 2020. Dias depois, instalou-se o estado de calamidade pública, com efeitos até o dia 31/12/2020, através do Decreto Legislativo 6, do dia 20/03/2020.

$\mathrm{Na}$ esteira dos inúmeros procedimentos de isolamento social decretados pelos governos estaduais e municipais, ante a inércia do governo federal, com o consequente fechamento do comércio e paralisação de inúmeros segmentos da produção de bens e serviços, viu-se o Poder Executivo Federal diante a necessidade de promover uma regulação dos contratos de trabalho vigentes, no intento de impedir a disseminação do desemprego em todo o país 4 . Nesse contexto, adveio a Medida Provisória 927, publicada em edição do DOU de 22/03/2020.

De partida, aquele diploma reconhece a pandemia como motivo de força maior, nos termos do art. 501 da CLT, antecipando-se numa interpretação açodada, capaz de reduzir os direitos rescisórios daqueles que foram dispensados, uma vez que os atos de fechamento do comércio e paralisação da atividade industrial decorreu de ato de poder público e, como tal, na dicção do art. 486, caput, da CLT, os direitos rescisórios restariam incólumes. Em verdade, como se verá

4 Como bem observa Costa (2020), a pandemia expôs "[...] por exemplo, dois problemas graves que impedem o combate da doença nas favelas brasileiras: a ausência de saneamento básico e a alta densidade de seres humanos por metro quadrado. Assim, direcionar recursos para a saúde e os setores apontados como gargalos é essencial para dinamizar a economia com a geração de empregos formais" (COSTA, 2020) 
adiante, bem diversamente a força maior, ajusta-se o caso aos ditames do Código Civil, capazes de deflagar a revisão contratual.

A estratégia seguida pelo Executivo foi a de empoderar o empregador, simplesmente desconsiderando princípios basilares do contrato de trabalho. A regra inscrita no art. 468 da CLT, no sentido que "só é lícita a alteração das respectivas condições por mútuo consentimento, e ainda assim desde que não resultem, direta ou indiretamente, prejuízos ao empregado, sob pena de nulidade da cláusula infringente desta garantia”, é manifestamente relegada, isso em nome daquele imperativo maior da manutenção dos empregado, objetivo que, manifestamente, não aconteceu.

Nesse sentido, foram feitas intervenções legais nos perfis do teletrabalho, antecipação das férias individuais, aproveitamento e antecipação de feriados e no banco de horas. Ressalte-se que há na Medida Provisória outras iniciativas complementares, a exemplo do diferimento do recolhimento do FGTS ou o afrouxamento das medidas necessárias à concessão de férias coletivas, iniciativas que não modificaram, substancialmente, a estrutura do contrato de trabalho, daí porque não serão objeto do presente ensaio. Ademais, ainda havia no corpo daquele diploma uma seção dedicada ao direcionamento do trabalhador para a qualificação profissional, iniciativa que, flagrantemente ilegal, foi logo abandonada pelo poder subscritor, revogando essa parte por meio da MP 928, publicada em 23/03/2020, dia seguinte à vigência da MP 927.

Voltando ao cerne da exposição, veja-se, por exemplo, o que ofertava a Medida Provisória 927 acerca do teletrabalho:

Art. $4^{\circ}$ Durante o estado de calamidade pública a que se refere $\mathrm{o}$ art. $1^{\mathrm{o}}$, o empregador poderá, a seu critério, alterar o regime de trabalho presencial para o teletrabalho, o trabalho remoto ou outro tipo de trabalho a distância e determinar o retorno ao regime de trabalho presencial, independentemente da existência de acordos individuais ou coletivos, dispensado o registro prévio da alteração no contrato individual de trabalho. 
No formato legal, a transformação do teletrabalho para o regime presencial faz-se mediante acordo entre as partes, através de aditivo contratual (CLT, art. $75-\mathrm{C}, \S 1^{\mathrm{o}}$ ). Esse mesmo comportamento imperativo se releva quando se trata da concessão de férias, podendo o empregador simplesmente suspender as férias ou licenças não remuneradas dos profissionais da área de saúde ou daqueles que desempenhem funções essenciais, através de comunicação formal por escrito ou por meio eletrônico, preferencialmente com antecedência de quarenta e oito horas (MP 927, art. $7^{\circ}$.)5. Do mesmo, assim funcionaria a antecipação de feriados civis (Art. 13). Criou-se, também, um banco de horas com prazo de até 18 meses para compensação de jornada não praticada, em desconformidade com o disposto no art. $59, \S 2^{\circ}$, da CLT, que estabelece um ano de prazo máximo.

Quando não atribui ao empregador o poder de modificar unilateralmente o contrato, a MP entrega essa poder à negocial bilateral, condição, no âmbito dos contratos de trabalho, manifestamente temerária, frente à sujeição do empregado ao poder patronal, tolhendo-lhe a livre iniciativa, ainda mais quando o próprio móvel da MP era a manutenção do emprego. Vejamos a hipótese do seu art. 26, com destaques nossos:

Art. 26. Durante o de estado de calamidade pública a que se refere o art. $1^{\circ}$, é permitido aos estabelecimentos de saúde, mediante acordo individual escrito, mesmo para as atividades insalubres e para a jornada de doze horas de trabalho por trinta e seis horas de descanso:

I - prorrogar a jornada de trabalho, nos termos do disposto no art. 61 da Consolidação das Leis do Trabalho, aprovada pelo Decreto-Lei ${ }^{0}$ 5.452, de 1943; e

II - adotar escalas de horas suplementares entre a décima terceira e a vigésima quarta hora do intervalo interjornada, sem que haja penalidade administrativa, garantido o repouso semanal remunerado nos termos do disposto no art. 67 da Consolidação das Leis do Trabalho, aprovada pelo Decreto-Lei no $5 \cdot 452$, de 1943.

5 Acerca do teletrabalho, considerando mesmo a legislação ordinária quanto ao tema, advertem Dacheri e Goldshmidt (2018, p. 16) que "embora a legislação trabalhista avance no sentido de definir o conceito e o regime de trabalho do teletrabalhador, normas de direito fundamental vêm sendo flexibilizadas, tendo em vista que a legislação não alcança, por exemplo, problemas envolvendo o controle de jornada e o respeito ao direito à desconexão, entre outros". 
Essa prorrogação de jornada, envolvendo profissionais da saúde, afigura-se gravíssima, pois, sabidamente, viola as condições mínimas de recomposição orgânica, submete os pacientes, consequentemente, à possibilidade erros na execução dos serviços $\mathrm{e}$ gera situação potencial e efetiva de acidentes do trabalho. Olvida-se aqui da presença obrigatória do ente sindical em negociação dessa natureza, conforme dita nossa Constituição Federal em seu art. $7^{\circ}$., itens XIII e XIV. Apesar disso, vale notar, com a devida surpresa, que essa Medida Provisória passou pelo crivo liminar do Supremo Tribunal Federal, que somente suspendeu a eficácia do art. 29, relativo à fiscalização do trabalho, abraçando a tese de que nesses momentos difíceis deve prevalecer a mantença dos empregos mesmo que, com todas as vênias, perca-se de vista a essencialidade do contrato de trabalho.

Guarda o contrato de trabalho determinadas peculiaridades tanto em seu aspecto interno quanto externo. Trata-se de um pacto que guarda, em sua origem, uma desigualdade essencial, posto que se destina à captação de um elemento singular, consistente na força de trabalho, irrestituível e de difícil remuneração. A história de sua gênese está diretamente relacionada com controle da jornada laboral e pela busca um pagamento digno pelas horas dispendidas em favor do empregador. Ademais, destina-se a equacionar um dilema inerente ao sistema capitalista de produção, relacionado aos princípios da livre iniciativa e do valor social do trabalho, estampados num único inciso logo $\operatorname{art.} 1^{0}$ da Constituição Federal (item IV). Por essa razão, ergue-se sempre ao largo do contrato celebrado entre patrão e empregado uma dimensão maior, de natureza coletiva, que daria ao empregado, parte mais vulnerável, a proteção jurídica contra o poder econômico. E essa dimensão coletiva, lamentavelmente, vem sendo solapada desde a edição da denominada "reforma trabalhista" (Lei 13.467/17), em nome da modernização das relações de trabalho no país. 
Entretanto, a par das críticas feitas, o fato é que a Medida Provisória 927 soçobrou $^{6}$. Restou incólume, contudo, uma questão: que mecanismos podemos acionar em situações de emergência como aquela que estamos vivenciando, sem dúvida a mais grave dos últimos cem anos. Como emprestar ao contrato de trabalho a devida flexibilidade, sem simplesmente destruir os fundamentos do direito do trabalho? É disso que vamos tratar na parte que segue.

\section{COMPATIBILIZANDO O DEVER DE RENEGOCIAR COM OS CONTRATOS INDIVIDUAIS DE TRABALHO: EM BUSCA DA EFETIVAÇÃO DOS PRINCÍPIOS CONSTITUCIONAIS EM TEMPOS DE CRISE}

Conforme dito linhas atrás, há que se compatibilizar os princípios da valorização do trabalho com a livre iniciativa. Contudo, esse esforço não pode desconsiderar o fato de que a relação de emprego formalmente constituída pressupõe um desequilíbrio genético, representado pelo princípio da alteridade, ressaltando que ao empregador cabe à assunção dos riscos da atividade econômica (CLT, art. $2^{\mathrm{o}}$, caput). Entretanto, convém destacar que a limitação a liberdade individual dos contratantes, mesmo na relação de emprego, não nos deve levar a posições extremadas, como esclarece Amauri Mascaro Nascimento (2011, p. 366):

A autodeterminação, como poder de escolha dos seus interesses, não pode deixar de sofrer restrições nas relações de trabalho. É controlada, mas não anulada. O ordenamento jurídico reconhece a superioridade contratual de uma das partes e tem instrumentos de

\footnotetext{
6 "A medida provisória (MP) n. 936 foi convertida já na citada lei n. 14.020 e se põe, historicamente, como alternativa encontrada pelo governo federal ante a repercussão negativa de sua intenção inicial - MP n. 927 (Brasil, 2020e) -, uma vez que visava, de forma clara e tendenciosa, apenas à proteção dos interesses do empresariado, sem nenhuma preocupação com os trabalhadores." (SOUZA, 2021) 
controle para que, adequadamente usados, possam oferecer um melhor equilíbrio entre os sujeitos do contrato.

Em que medida essa responsabilidade elidiria o empregado de comparticipar de um dever de renegociação contratual?

Destaque-se que no âmbito da legislação trabalhista a regulação das alterações em caso de força maior é tímida. $\mathrm{O}$ art. 502 da CLT, por exemplo, cuidando da força maior, prevê um corte muito discreto na indenização devida em caso de despedimento (multa de 40\% sobre o FGTS, atualizando o dispositivo para o atual estágio de regulação dos direitos rescisórios, conforme o item II do referido artigo). $\mathrm{O}$ art. 503 daquele mesmo diploma dá uma opção ao empregador, consistente numa redução dos salários dos seus empregados não superior a $25 \%$, desde que respeitado o salário mínimo. Aqui, com efeito, há que se falar em superação de tal previsão frente o dispositivo constitucional superveniente, ao proclamar que eventuais reduções salariais somente se perfectibilizem por meio de norma coletiva (Art. $7^{\circ}, \mathrm{CF} / 88$ ).

Num cenário de crise econômica, seja ela generalizada, setorial ou mesmo pontual em determinada empresa, o ordenamento jurídico deve dispor às partes medidas necessárias à preservação dos empregados e, de outro lado, à mantença da atividade econômica. Somente assim, diante dessa ambiência de crise, que se poderá falar na articulação razoável entre os dois princípios estampados no primeiro artigo de nossa Constituição, ora em destaque. Se a legislação especial do trabalho não nos socorre, resta-nos buscar alternativas na lei civil.

Recentemente, digno de nota é o surgimento da chama "lei da liberdade econômica", a 13.874, de 20 de setembro de 2019, que inovou em relação aos parâmetros hermenêuticos dos contratos, inclusive os trabalhistas (Art. $1^{\circ}, \S 1^{\circ}$ ). No parágrafo seguinte, afirmase: "Interpretam-se em favor da liberdade econômica, da boa-fé e do respeito aos contratos, aos investimentos e à propriedade 
todas as normas de ordenação pública sobre atividades econômicas privadas" (com destaques nossos).

A lei da liberdade econômica ainda promoveu inúmeras mudanças pontuais em diversos diplomas legislativos vigentes, destacando, para os fins deste ensaio, as seguintes alterações em artigos do Código Civil, mais uma vez com destaques nossos:

Art. 113. Os negócios jurídicos devem ser interpretados conforme a boa-fé e os usos do lugar de sua celebração. (redação sem alteração)

$\S 1^{\circ}$ A interpretação do negócio jurídico deve lhe atribuir o sentido que:

I - for confirmado pelo comportamento das partes posterior à celebração do negócio;

II - corresponder aos usos, costumes e práticas do mercado relativas ao tipo de negócio;

III - corresponder à boa-fé;

IV - for mais benéfico à parte que não redigiu o dispositivo, se identificável; e

V - corresponder a qual seria a razoável negociação das partes sobre a questão discutida, inferida das demais disposições do negócio e da racionalidade econômica das partes, consideradas as informações disponíveis no momento de sua celebração.

$\S 2^{\circ}$ As partes poderão livremente pactuar regras de interpretação, de preenchimento de lacunas e de integração dos negócios jurídicos diversas daquelas previstas em lei." (NR)

"Art. 421. A liberdade contratual será exercida nos limites da função social do contrato.

Parágrafo único. Nas relações contratuais privadas, prevalecerão o princípio da intervenção mínima e a excepcionalidade da revisão contratual." (NR)

"Art. 421-A. Os contratos civis e empresariais presumem-se paritários e simétricos até a presença de elementos concretos que justifiquem o afastamento dessa presunção, ressalvados os regimes jurídicos previstos em leis especiais, garantido também que:

I - as partes negociantes poderão estabelecer parâmetros objetivos para a interpretação das cláusulas negociais e de seus pressupostos de revisão ou de resolução;

II - a alocação de riscos definida pelas partes deve ser respeitada e observada; $\mathrm{e}$

III - a revisão contratual somente ocorrerá de maneira excepcional e limitada."

Em relação a tais dispositivos, podemos inferir que o caráter da boa-fé, especificamente sob sua feição objetiva, permanece em destaque quando se trata do exercício hermenêutico voltado à precisão dos sentidos dos contratos. Qualquer modalidade revisional somente 
pode ser feita em caráter excepcionalíssimo, daí porque, no âmbito trabalhista, considerando que a regulação dos riscos é pré-fixada, dada a alteridade, via de regra, não há que se falar sequer em formação de distribuição dos ônus desses riscos de forma diversa, como preconiza a nova regra ditada pelo diploma em análise.

Se houver, na seara trabalhista, norma referente a essa divisão, deverá ela ser feita de maneira a ampliar, nunca restringir, as garantias para o crédito trabalhista, vendando-se, por exemplo, eventual revisão do contrato, mesmo em situações de crise. Portanto, à luz do princípio da máxima autonomia contratual, pode-se restringir a revisão do contrato por parte do empregador, se assim constar do contrato firmado entre as partes ou de eventual acordo ou convenção coletiva. Não sendo esta a hipótese, abre-se a possibilidade do pedido de revisão e renegociação, na forma que segue.

Ora, já dissemos que o fundamento do direito à renegociação decorre da aplicação do princípio da boa-fé objetiva (CCB, art. 422). Esse princípio se encontra imbricado com a própria funcionalidade social atribuída aos contratos em geral. Importante, nesse passo, ressaltar as ponderações de Anderson Shreiber (2018, p. 392):

\begin{abstract}
Quando se alude, todavia, a uma dimensão comportamental do desequilíbrio contratual, é inevitável que entre em cena a boa-fé objetiva como cláusula geral que impõe aos contratantes um comportamento colaborativo e transparente, voltado à efetiva realização do fim contratual.[...] não se pode deixar de notar que tanto o dever de avisar prontamente a contraparte acerca do desequilíbrio contratual identificado, quanto o dever de ingressar em renegociação com vistas a obter o reequilíbrio do contrato constituem deveres de conduta que, conquanto instrumentalizados à recuperação do equilíbrio contratual, derivam, a rigor, da necessidade de que as partes cooperem entre si para a concretização do escopo contratual.
\end{abstract}

A boa-fé no âmbito dos contratos, inclusive os trabalhistas, envolve, naturalmente, obrigações bilaterais: o dever do empregador de comunicar prontamente ao empregado e ao ente sindical correlato (se houver) da ocorrência de situação de desequilíbrio contratual grave, nos termos dos arts. 478 e 479 do $\mathrm{CCB}$, suscitando uma 
negociação; de outro lado, cabe ao empregado e ao ente sindical eventualmente envolvido na querela, responder às propostas formuladas, contribuindo para a superação da situação de desequilíbrio instalada:

O dever de renegociar constitui, em outras palavras, um dever de ingressar em renegociação, informando prontamente o fato que a enseja e formulando um pleito de revisão do contrato, ou analisando e respondendo, com seriedade, ao pleito apresentado pelo outro contratante. É em essência, um dever de comunicar, de pronto, a existência do desequilíbrio contratual e ingressar em tratativas para encontrar a melhor forma de superá-lo, em consonância com a boa-fé objetiva (SHREIBER, 2018, p. 397).

E nem se diga que há entraves relacionados a essa possibilidade de negociação no direito do trabalho, uma vez que as decisões sindicais devem ser tomadas sempre em esfera coletiva. A CLT possui um mecanismo que pode ser deflagrado nas empresas, objetivando a celebração de acordos coletivos. Vejamos:

Art. 617 - Os empregados de uma ou mais empresas que decidirem celebrar Acordo Coletivo de Trabalho com as respectivas empresas darão ciência de sua resolução, por escrito, ao Sindicato representativo da categoria profissional, que terá o prazo de 8 (oito) dias para assumir a direção dos entendimentos entre os interessados, devendo igual procedimento ser observado pelas empresas interessadas com relação ao Sindicato da respectiva categoria econômica.

$\S 1^{\circ}$ Expirado o prazo de 8 (oito) dias sem que o Sindicato tenha se desincumbido do encargo recebido, poderão os interessados dar conhecimento do fato à Federação a que estiver vinculado o Sindicato e, em falta dessa, à correspondente Confederação, para que, no mesmo prazo, assuma a direção dos entendimentos. Esgotado esse prazo, poderão os interessados prosseguir diretamente na negociação coletiva até final.

$\S 2^{\circ}$ Para o fim de deliberar sobre o Acordo, a entidade sindical convocará assembleia geral dos diretamente interessados, sindicalizados ou não, nos termos do art. 612.

Ademais, essa nova perspectiva não elide a via judicial para a deflagração da negociação. A interpretação sistemática dos dispositivos acima nos deixa antever a possibilidade de uma ação 
revisional quanto aos contratos de trabalho, movida pelo empregador que estiver atravessando uma situação contingencial que leve a significativo desequilíbrio contratual. $\mathrm{Na}$ hipótese de nãocomparecimento do empregado ou do ente sindical respectivo, a ser citado, quando for o caso, na condição de litisconsorte necessário, caberá ao judiciário prolatar decisão que module os efeitos do contrato visando a mantença dos empregos e o funcionamento das empresas. Algo semelhante, diga-se, ao antigo poder normativo que a Justiça do Trabalho nas hipóteses de dissídios coletivos. Ressalte-se que a peça de ingresso deverá indicar, a partir de elementos concretos, a intenção de renegociar e vir acompanhada de proposta(s) visando a recuperação judicial dos contratos de trabalho, bem como que essas medidas de eventual restrição devem ser sempre movidas por caráter de curta duração, com o monitoramento constante dos órgãos de fiscalização do trabalho e do Ministério Público do Trabalho, a quem se acolha, igualmente, a composição da lide na qualidade de fiscal da lei.

De ressaltar, enfim, que o Poder Judiciário do Trabalho, historicamente, é vocacionado à conciliação, possuindo centros especializados para o tratamento de demandas envolvendo coletividades de trabalhadores e fazendo uso das modernas técnicas visando a obtenção de acordos com o selo da coisa julgada material.

\section{CONSIDERAÇÕES FINAIS}

Este trabalho teve como objetivo repensar os pilares e a proteção contratual do direito civil clássico, a partir da construção doutrinária de um "dever de renegociar", aplicando essa noção aos casos em que se impõe uma revisão de cláusulas nos contratos de trabalho em decorrência de situações contingenciais, geradoras de 
graves desequilíbrios contratuais, a exemplo daquelas vivenciadas pela emergência em saúde pública pela pandemia do Coronavírus.

As operações econômicas estão intrinsecamente relacionadas a regulação contratual. Com efeito, a evolução da teoria dos contratos se dá a medida em que se expandem as atividades produtivas e seguindo o contexto econômico - social em que se insere. E os contratos de trabalho, hodiernamente, ocupam um sistema ligado à dimensão do direito econômico, cujos parâmetros hermenêuticos devem ser compartilhados, desde a vigência da denominada "lei da liberdade econômica".

Se num primeiro momento imperava a ideologia liberal, da autonomia privada irrestrita onde o que as partes firmavam era lei, não importando o conteúdo daquela avença, com o decorrer do tempo, o contrato evoluiu, e as políticas voltam-se para a harmonização do individual com o social através de normas de ordem pública e os pilares do direito contratual clássico são modificados, a partir da limitação da autonomia privada levado em consideração os princípios da função social, boa - fé objetiva e equilíbrio econômico. É esse paradigma que é trazido para o corpo do Código Civil de 2002 e reforçado pela legislação superveniente, sendo necessária sua integração ao direito do trabalho.

Nosso ordenamento jurídico, muito embora traga um arcabouço normativo que permite o equilíbrio contratual ainda reage de forma tímida à necessidade de justiça nos contratos, especialmente nas relações de emprego, sendo certo que ainda podemos perceber resquícios das teorias voluntaristas nos seus artigos, notadamente na parte voltada para a teoria da onerosidade excessiva e fincada na ideia de que ao empregador cabe à assunção integral dos riscos da atividade econômica.

O direito de pleitear a renegociação do contrato parece ser ferramenta hábil à superação da crise por atender tanto ao aspecto socializante dos contratos (preservação de empresas, estímulo à atividade econômica, empregos etc), como privilegiar a boa - fé dos contratantes, já que as partes devem agir de forma transparente e 
Dever De Renegociar Contratos De Trabalho Como Possibilidade De Superação...

colaborativa, a fim de mitigar de pronto os danos sofridos, a partir do binômio dever de informar a ocorrência do desequilíbrio - dever de responder à renegociação.

Nesse sentido, a proposta deste ensaio é justamente admitir não apenas a abertura de um procedimento extrajudicial de renegociação de cláusulas contratuais, chancelado pelo ordenamento jurídico vigente, como também, possibilitar que, caso essa via não chegue a bom termo, permitir que se provoque a Justiça do Trabalho para que se instale algo como que um "regime de recuperação judicial dos empregos", a partir de uma flexibilização operada com a supervisão do Estado, através da atuação sempre qualificada dos órgãos que integram esse ramo do judiciário.

Enfim, o momento de crise pandêmica por que passamos, sem paralelo nos últimos cem anos, exige a adoção de medidas arrojadas, visando especialmente a preservação da dignidade da pessoa humana. Nesse gênero, temos trabalhadores e empregadores. E o sistema jurídico civil, na perspectiva dos autores, já está habilitado a desenvolver soluções de curta duração, sem desprivilegiar os cânones constitucionais da proteção ao trabalho e ao direito de participação das entidades sindicais no processo de renegociação.

Data de Submissão: 14/08/2020

Data de Aprovação: 09/12/2020

Processo de Avaliação: double blind peer review

Editor Geral: Jailton Macena de Araújo

Editor de Área: Alana Ramos Araújo

Assistente Editorial: Jaime W. Rodrigues Mangueira 


\section{REFERÊNCIAS}

CAPPELLETTI, Mauro. Juízes legisladores?. Porto Alegre: Sergio Antonio Fabris Editor, 1999.

COSTA, Simone da Silva. (2020). Pandemia e desemprego no Brasil. Revista de Administração Pública, 54(4), 969-978. Epub August 28, 2020.https://dx.doi.org/10.1590/0034-761220200170. Acesso em 03 dec 2020.

DACHERI, Emanueli; GOLDSCHMIDT. Teletrabalho: uma possibilidade de inclusão socioeconômica do trabalhador.Prim@ Facie. João Pessoa: PPGCJ, v. 17. N. 35, 2018. Disponível em: https://periodicos.ufpb.br/index.php/primafacie/article/view/4016 o/20919. Acesso 03 dec 2020.

FEITOSA, Maria Luiza Alencar Mayer. Humanização do direito civil constitucional ou por um direito civil social. Lineamentos introdutórios. In Revista de Direito Civil Contemporâneo: RDCC, São Paulo, v. 4,n.11, abr.jun, 2017.

MATTIETO, Leonardo. O direito civil constitucional e a nova teoria dos contratos. In TEPEDINO, Gustavo (coord). Problemas de direito civil constitucional. Rio de Janeiro: Renovar, 2000.

MORAES, Maria Celina Bodin de. Na medida da pessoa humana: estudos de direito civil constitucional. Rio de Janeiro: Renovar, 2010

NASCIMENTO, Amauri Mascaro. Direito contemporâneo do trabalho. São Paulo: Saraiva, 2011.

PERLINGIERI, Pietro. Perfis do direito civil: introdução ao direito civil-constitucional. 3ed. Rio de Janeiro: Renovar, 2007.

RIPERT, Georges. A regra moral nas obrigações civis. Campinas: Bookseller, 2000.

ROPPO, Enzo. O contrato. Coimbra: Almedina, 2009.

RULLI NETO, Antonio. Função social do contrato. São Paulo: Saraiva, 2011.

SANTIAGO, Murilo Carvalho. Considerações sobre o contrato coativo. In Revista da faculdade de direito da UFMG, Belo Horizonte, v. 27, n.21, mai, 1979. 
Dever De Renegociar Contratos De Trabalho Como Possibilidade De Superação...

SCHREIBER, Anderson. Equilíbrio contratual e dever de renegociar. São Paulo: Saraiva Educação, 2018.

SOUZA, Diego O. As dimensões da precarização do trabalho em face da pandemia de

Covid-19. Trabalho, Educação e Saúde, v. 19, 2021, eoo311143.

DOI: 10.1590/1981-7746-soloo311. Disponível em:

http:www.tes.epsjv.fiocruz.br. Acesso em 03 dec 2020.

TEPEDINO, Gustavo. Premissas metodológicas para a constitucionalização do direito civil. In. Temas de direito civil. 3 . Ed. Rio de Janeiro: Renovar, 2004.

THEODORO JR, Humberto. O contrato e sua função social: a boa-fé objetiva no ordenamento jurídico e a jurisprudência contemporânea. Rio de Janeiro: Gen Método, 2014.

TOSCANO DE BRITO, Rodrigo. Equivalência material dos contratos civis, empresariais e de consumidor. São Paulo: Saraiva, 2007. 


\title{
Duty To Renegotiate Employment Contracts As A Possibility To Overcome The Economic Crisis Resulting From The Coronavirus Pandemic
}

\author{
Paulo Henrique Tavares da Silva
}

\author{
Juliana Coelho Tavares Marques
}

\begin{abstract}
The article seeks for alternatives to the economic crisis scenario that shows increasing levels of employment contracts termination resulting from the loss of economic and financial resources of companies, prevented from opening due to restrictive measures as a consequence of public health emergency status decreed in Brazil, in order to face Sars-Cov-2 virus pandemic (Coronavirus). It is explored a possibility of a duty to renegotiate ongoing work contracts, aiming at maintaining jobs and company activities, based on current Brazilian constitutional principles, such as socialization and social function of institutions, based on a dialogue between civil law and labor law. The study has an exploratory and prospective nature, using the deductive approach, with the management of documentary research techniques, having as object of study the legislation, doctrines and jurisprudential resources. In the end, it is admitted that the duty to renegotiate employment contracts is a tool capable of overcoming a crisis, as it addresses the socializing aspect of contracts and privileges the good faith of the contractors, without disregarding the constitutional canons of labor protection and the right of union entities to participate in the renegotiation process.
\end{abstract}

Keywords: Duty to Renegotiate. Employment Contracts. Economic Crisis. Coronavirus.

DOI: https://doi.org/ 10.22478/ufpb.1678-2593.2021v2on43.54543

Conteúdo sob licença Creative Commons: Attribuition-NonCommercial-NoDerivative 4.0 International (CC BY-NC-ND 4.0) 